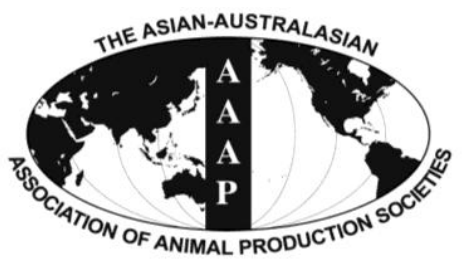

Asian-Aust. J. Anim. Sci.

Vol. 25, No. $7: 1029$ - 1037 July 2012

www.ajas.info

http://dx.doi.org/10.5713/ajas.2011.11287

\title{
Substantial Effect of Melanin Influencing Factors on In vitro Melanogenesis in Muzzle Melanocytes of Differently Colored Hanwoo
}

\author{
Touseef Amna, Kyoung Mi Park, In-Kyung Cho ${ }^{1}$, Tae Jeong Choi ${ }^{2}$, \\ Seung Soo Lee ${ }^{2}$, Kang-Seok $\mathrm{Seo}^{3}$ and Inho Hwang* \\ Department of Animal Science and Institute of Rare Earth for Biological Application, \\ Chonbuk National University, Jeonju, 561-756, Korea
}

\begin{abstract}
The present study was designed to investigate the effect of $\alpha$-melanocyte-stimulating hormone ( $\alpha$-MSH), nitric oxide (NO) and L-cysteine on melanin production and expression of related genes MC1R, Tyr, Tyrp-1 and Tyrp-2 in muzzle melanocytes of differently colored three native Hanwoo cattle. Muzzle samples were taken from black, brindle and brown Hanwoo and purified melanocytes were cultured with $\alpha$-MSH, nitric oxide and L-cysteine at $100 \mathrm{nM}, 50 \mu \mathrm{M}$ and $0.07 \mathrm{mg} / \mathrm{ml}$ of media respectively. The amounts of total melanin, eumelanin and mRNA expression at Tyr, Tyrp-1, Tyrp-2 and MC1R levels were quantified. $\alpha$-MSH and nitric oxide significantly increased $(\mathrm{p}<0.05)$ the amount of total melanin in black and brindle whereas eumelanin production in brown Hanwoo muzzle melanocytes. On the contrary, L-cysteine greatly $(\mathrm{p}<0.05)$ depressed the eumelanin production in black color but increased in brown. Simultaneously, up regulation of Tyr by nitric oxide and $\alpha-\mathrm{MSH}$ and down regulation of Tyr, Tyrp-2 and MC1R genes by L-cysteine were observed in muzzle melanocytes of all three phenotypes. The results of this study revealed nitric oxide and $\alpha$-MSH contribute hyper-pigmentation by enhancing eumelanogenesis whereas L-cysteine contributes to pheomelanin production in different colored Hanwoo muzzle melanocytes. (Key Words: Melanogenesis, Nitric Oxide, Hanwoo Muzzle, Melanocytes, Cysteine)
\end{abstract}

\section{INTRODUCTION}

Coat color and pigmentation on various body parts of animals are a readily observable visual phenotype and are mostly considered for selection criteria because even small changes in coat color influences the organism's ability to survive or reproduce (Endler, 1993; Safran and McGraw, 2004) in domestic and wild animals. Becerril et al. (1993) demonstrated that the degree of white spotting in Holstein cattle influenced the level of milk yield and reproductive performance in terms of solar radiation in the environment (Becerril et al., 1993).

\footnotetext{
* Corresponding Author: Inho Hwang.

E-mail: inho.hwang@jbnu.ac.kr

${ }^{1}$ Department of Food and Nutrition, Nambu University, Gwangju 506-706, Korea.

${ }^{2}$ National Institute of Animal Science, RDA, Cheonan 330-801, Korea.

3 Department of Animal Science and Technology, Suncheon National University, Suncheon, 540-742, Korea.

Submitted Aug. 19, 2011; Accepted Dec. 27, 2011; Revised Jan. 30, 2012
}

All mammalian pigmentation result from the pigment producing cells (melanocytes) and therefore, variations in vertebrate skin and hair color are due to varied amounts of eumelanin (brown/black) and pheomelanin (red/yellow) produced by the melanocytes. Melanocytes originate in the neural crest and migrate to dermis during mammalian development (Jackson, 1994; Klungland and Vage, 2000). Pigmentation biology has been extensively studied in mice and humans to understand its pleiotropic effects (Jackson, 1997). Mammalian pigmentation model systems have served to study molecular, cellular and developmental processes in detail (Silvers, 1979). Till date, over 150 genes known for animal coat color and patterning have been identified and reported (Roulin, 2004; Mundy, 2005; Hoekstra, 2006; Protas, 2008).

Few earlier studies in vertebrate species have revealed the role of melanocortin 1 receptor $(M C 1 R)$, formerly named by alpha melanocyte stimulating hormone receptor $(\alpha-M S H R)$ in the regulation of eumelanin and pheomelanin pigment synthesis in melanocytes (Robbins et al., 1993).

The Korean Hanwoo cattle exhibit three different coat 
color phenotypes viz., black, brindle and yellowish-brown and concomitant muzzle color of black, yellowish-brown and black spotted brown, respectively (Seo et al., 2007). Our group previously reported the molecular variation in pigmentation genes (TYRPI (exon 5) and MC1R genes) in Hanwoo cattle and Black Angus. Sequence variants particularly in $M C 1 R$ were reported to be associated with total melanin and eumelanin in breeds (Mohanty et al., 2008). Pigmentation genes such as TYR (tyrosinase), TYRP-1 (tyrosinase-related protein 1), DCT (previously TYRP-2 or tyrosinase-related protein 2) and $M C 1 R$ play a vital role in cattle melanogenesis (Seo et al., 2007). In addition, both $\alpha$-MSH and nitric oxide were reported to accelerate the production of eumelanogenic melanin (Hunt et al., 1995; Thody and Graham, 1998; Ito et al., 2000) while L-cysteine tunes up the pheomelanin production (Hunt et al., 1995). The present study was designed on the basis of our previous findings (Mohanty et al., 2008) and to further investigate the effect of $\alpha$-melanocyte-stimulating hormone $(\alpha-\mathrm{MSH})$, nitric oxide and L-cysteine on melanin production and expression of related genes MC1R, Tyr, Tyrp-1 and Tyrp-2 in muzzle melanocytes of Hanwoo breeds (i.e., black, brindle and brown). Earlier workers have studied the diverse patterns of mammalian coat color by the quantity and distribution of two types of organic pigments such as eumelanin (black to brown) and pheomelanin (yellow to red) (Ito, 2003; Barsh, 2006). Both are produced by melanocytes in the hair bulbs and basal epidermis. We herein report that pigmentation in melanocytes is dependent on the melanogenic factors such as $\alpha-\mathrm{MSH}$ and nitric oxide which adds eumelanin and pheomelanin to the melanocytes respectively. To the best of our knowledge our group is the first to have studied the effect of abovementioned factors on the production of melanin in muzzle melanocytes of native Korean Hanwoo breeds.

\section{MATERIAL AND METHODS}

\section{Sampling and cell culture}

Muzzle samples were taken from three native Hanwoo cattle which had the phenotype of black, brindle and brown coat color, respectively. The muzzle samples were collected from the experimental animals of the Chonbuk Livestock Research Station after slaughter with the kind permission of ethical committee of Chonbuk National University. Approximately $2 \times 2 \mathrm{~cm}$ muzzle samples were collected from the slaughtered animals. After sampling the tissues were ice-packed supplemented with antibiotics. The collected samples were transferred to the laboratory within $40 \mathrm{~min}$ for further processing. The samples were processed for melanocytes isolation by the procedure as described by Ian Freshney (Ian Freshney, 1994) with suitable modifications. Briefly, muzzle samples were washed with sterile D-PBS (Gibco) to remove potential surface contamination. Most of the fat was trimmed off and discarded.

The muzzle tissues were cut into pieces (approximately $5 \times 5 \mathrm{~mm}$ ) and cultured with $0.25 \%$ trypsin solution (Gibco) at $4^{\circ} \mathrm{C}$ for $24 \mathrm{~h}$ and rocked gently every after $1 \mathrm{~h}$. After incubation the fragments were taken into a dry sterile petridish with epidermal side down and the dermis was cleaned. Further, the tissues were put into $0.02 \%$ EDTA and vortexed gently to disintegrate the cells and centrifuged at $350 \times \mathrm{g}$ for 5 min. The pellets were re-suspended in melanocyte medium DMEM (Gibco) supplemented with $2.5 \%$ fetal bovine serum (FBS, Gibco), $2 \mathrm{mM}$ glutamine, $1 \mathrm{mM}$ sodium pyruvate, $1 \%$ non-essential amino acids, $2.5 \mathrm{ng} / \mathrm{ml}$ epidermal growth factor, $25 \mu \mathrm{g} / \mathrm{ml}$ bovine pituitary extract, 10 ng/ml Tetra-decanoy1 phorbol acetate (TPA), $100 \mathrm{U} / \mathrm{ml}$ penicillin, $100 \mu \mathrm{g} / \mathrm{ml}$ streptomycin, plated into uncoated tissue culture flasks (Falcon, Bacton Dickson Labware, Franklin Lakes, NJ, USA) and incubated in a $\mathrm{CO}_{2}$-regulated incubator (Thermo Electron Corporation, Revco, USA) in humidified $95 \%$ air $/ 5 \% \quad \mathrm{CO}_{2}$ atmosphere. Bovine pituitary extract (BPE) contains a variety of growth factors and hormones. So BPE was added to supplement the growth factors to the medium. In case of contamination with fibroblasts cells the culture medium was supplemented with geneticin (Sigma, USA) at a concentration of $100 \mu \mathrm{g} / \mathrm{ml}$ for 3 to 4 days. The pure cells were then subcultured. Finally the culture medium was supplemented with $15 \%$ horse serum and $2.5 \%$ fetal bovine serum to enhance the cell growth. Medium was changed after three days in a week.

\section{Treatment}

The second passaged cells $\left(2.5 \times 10^{5}\right)$ seeded into confocal dishes (Falcon, Bacton Dickson Labware, Franklin Lakes, NJ, USA) were allowed to attach overnight and subjected to three different treatments i.e. $\alpha-\mathrm{MSH}$, nitric oxide donor (sodium nitroprusside SNP) and L-cysteine. The dosage for $\alpha$-MSH and SNP were $100 \mathrm{nM}$ and $50 \mu \mathrm{M}$ for each dish respectively. L-cysteine was added as 0.07 $\mathrm{mg} / \mathrm{ml}$ of media. For $\alpha-\mathrm{MSH}$ treatment the media used was without bovine pituitary extract (BPE) and treatment was done after $12 \mathrm{~h}$ of culture. For nitric oxide treatment, sodium nitroprusside (SNP) was used as a donor and the cells were treated after $24 \mathrm{~h}$ in culture. For L-cysteine, treatment was done after $12 \mathrm{~h}$ of culture in Dulbecco's (cysteine free) media. In controls only medium was replaced with fresh medium after $24 \mathrm{~h}$. All the experiments were done in triplicates along with suitable controls.

\section{Melanin measurements}

Total melanin in the cell suspension was measured spectrophotometrically according to procedure described in our previous publication (Mohanty et al., 2008). All the 
measurements were performed in triplicates. Briefly, $200 \mu \mathrm{l}$ of cell suspension $\left(4 \times 10^{5}\right.$ cells $)$ was taken and to this $2 \mu \mathrm{l}$ of soluene:water $(9: 1 \mathrm{v} / \mathrm{v})$ mixture was added and mixed properly $(\sim 10 \mathrm{~s})$. The mixed samples were placed in a water bath maintained at $80^{\circ} \mathrm{C}$ for $30 \mathrm{~min}$; the samples were taken out, remixed properly and kept again in the same water bath for further $15 \mathrm{~min}$. Finally, samples were cooled at room temperature. Standards were also processed in the same way. Absorbance was measured at 500 and $650 \mathrm{~nm}$ by spectrophotometer using sepia melanin as the standard.

For eumelanin estimation, permanganate oxidation was performed to obtain pyrrole-2, 3, 5-tricarboxylic acid (PTCA) and its quantification by HPLC was in accordance with earlier established procedures (Ito and Fujita, 1985; Mohanty et al., 2008). Briefly, $200 \mu \mathrm{l}$ cell suspensions $\left(4 \times 10^{5}\right.$ cells) were taken and to this $1 \mathrm{ml}$ of $1 \mathrm{M} \mathrm{H}_{2} \mathrm{SO}_{4}$ was added, the resulting solution was mixed properly. To $0.1 \mathrm{ml}$ of BSA $\left(20 \mathrm{mg} / \mathrm{ml}\right.$ in $\left.\mathrm{H}_{2} \mathrm{O}\right), 15 \mathrm{ml}$ of $3 \% \mathrm{KMnO}_{4}(0.15 \mathrm{~g}$ in $5 \mathrm{ml} \mathrm{H}_{2} \mathrm{O}$ ) was added and mixed properly, purple color disappears. Again, $15 \mathrm{ml}$ of $3 \% \mathrm{KMnO}_{4}$ was added and mixed for $10 \mathrm{~min}$. After that $100 \mathrm{ml}$ of $10 \% \mathrm{Na}_{2} \mathrm{SO}_{3}$ was added. Finally, $7 \mathrm{ml}$ of peroxide free Di-ethyl ether was added and mixed. The organic phase was separated and collected in a separate tube. This step was repeated. The collected organic phase was dried under a steam of nitrogen. To the organic residue, $300 \mathrm{ml}$ de-ionized $\mathrm{H}_{2} \mathrm{O}$ was added and samples were filtered through $0.45 \mu \mathrm{m}$ filter. HPLC (LC-20AD, Communication bus module, CBM-20A, Shimadzu, Japan) was performed at $45^{\circ} \mathrm{C}$ using a pheomenex RP-C18 column $(250 \mathrm{~mm} \times 4.6 \mathrm{~mm}, 7 \mu \mathrm{m}$ particle size) with a flow rate of $0.8 \mathrm{ml} / \mathrm{min}$ using isocratic pump. The mobile phase consisted of $0.01 \mathrm{M}$ potassium phosphate buffer ( $\mathrm{pH}$ 2.1): methanol 98:2 (v/v). $20 \mu \mathrm{l}$ of sample was injected and PTCA peak was detected at 269 nm. A standard curve was obtained using Sepia melanin (Sigma) and the retention time of the PTCA peak was established by pre-running a PTCA standard. All estimations were performed in triplicate and the average values were used for analysis in this study as described earlier (Mohanty et al., 2008). The PTCA values obtained were multiplied by a factor of 50 to obtain the eumelanin values (Ito and Fujita, 1985).

\section{mRNA expression}

Total RNA was extracted from $10^{6}$ cells of each breed using with Trizol solution (GIBCO-BRL, Burlington, ON, Canada) according to the manufacturer's specifications (Chomczynski and Sacchi, 1987). First strand cDNA was synthesized from $1 \mu \mathrm{g}$ of the total RNA using the M-MLV Reverse transcriptase with the anchored oligo $d(T)$ primer. The mRNA expression of selected genes was measured by reverse transcription polymerase chain reaction (RT-PCR). The PCR program initially started with a $94^{\circ} \mathrm{C}$ denaturation for $4 \mathrm{~min}$, followed by 20 to 42 cycles of $94^{\circ} \mathrm{C} / 45 \mathrm{~s}$, Ta ${ }^{\circ} \mathrm{C} / 45 \mathrm{~s}, 72^{\circ} \mathrm{C} / 1 \mathrm{~min}$. Linear amplification range for each gene was tested on the adjusted cDNA and here primer sequences, optimal PCR annealing temperatures (Ta) and cycle number are omitted. After electrophoresis of PCR products, the gels were digitalized (VersaDoc 3000, RioRad, USA) and relative density was determined against an arbitrary unit (Quantity One, Bio-Rad, v4.62, USA).

\section{Confocal microscopy}

Confocal microscopy was performed according to the standard procedure. Briefly, a portion of cells $\left(1 \times 10^{6}\right.$ cells $)$ was taken and centrifuged to get the pellet. Supernatant was discarded and the pellet was suspended into phosphatebuffered saline (PBS) and gently shaken at room temperature. PBS was removed and cells were re-suspended into the same buffer, this step was repeated twice. Next, the PBS was removed and pellet was transferred into the ethanol $(1 \mathrm{ml})$ at $-20^{\circ} \mathrm{C}$. The cells were kept in ethanol for 15 to $20 \mathrm{~min}$ at $-20^{\circ} \mathrm{C}$. After $20 \mathrm{~min}$ the ethanol was discarded and the cells were rehydrated with PBS at room temperature for $15 \mathrm{~min}$. Finally the PBS was removed and cells were stained with Propidium Iodide. A cover slip was used to distribute the dye evenly on the slide and poly-1lysine was used for the fixation. Samples were incubated at $37^{\circ} \mathrm{C}$ for $30 \mathrm{~min}$ in dark. The cover slip was removed and the fixed cells were rinse briefly with PBS to remove the unbound dye. Excessive liquid was removed from the slides by gently blotting around the samples with an absorbent tissue. The effect of treatments on the cells was assessed by propidium iodide staining after visualization under confocal microscope (Carl Zeiss, LSM 510 META, Germany) at regular time intervals viz., 24, 48, 72 and $96 \mathrm{~h}$.

\section{Statistical analysis}

Least square means of total melanin and eumelanin as a function of breeds in samples were calculated by using a general linear model (SAS, 1997), and the significance was evaluated by a pairwise difference analysis at $\mathrm{p}<0.05$.

\section{RESULTS}

Melanocyte cells (2nd passage) were grown to confluence $(\sim 80 \%)$ and were then subjected to three different treatments i.e. $\alpha-\mathrm{MSH}$, nitric oxide donor (SNP) and L-cysteine as aforementioned in the in the materials and methods. All the experiments were carried out in triplicates along with suitable controls. The culture protocol that was employed enabled us to establish and maintain melanocytes from Hanwoo muzzle under in vitro conditions up to several months. Morphology of the cultured cells was evaluated throughout the incubation period. Primary cells were maintained in basal medium with $2.5 \%$ fetal bovine serum. 

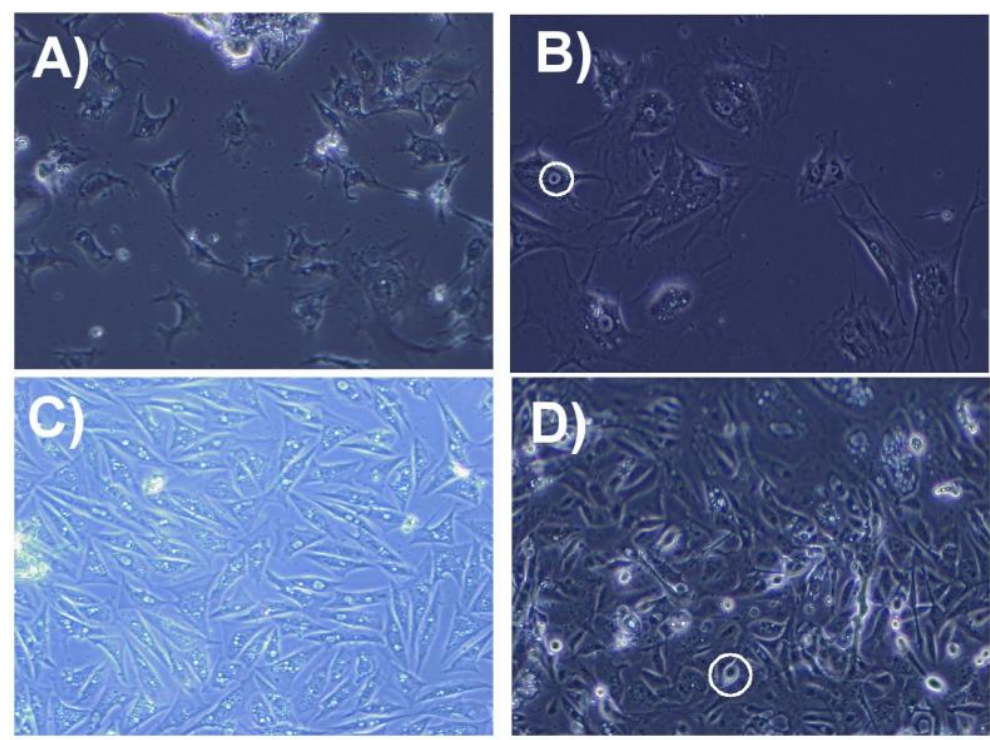

Figure 1. Morphological pattern of melanocytes isolated from Hanwoo muzzles of different breeds. The cells were selectively grown in basal media with $2.5 \%$ FBS after $14 \mathrm{~d}$ whereas fibroblast and keratinocytes disappeared after $7 \mathrm{~d}$. (a) Primary cells seen here are with high dendricity, dendrites connecting each other, $\times 100$. (b) 1st passage cells maintained in basal medium with $5 \%$ serum concentration. The cells showed maturation, high dendriticity and slight accumulation of melanin in the circles, $\times 200$. (c) Mostly dividing cells; polygonal to elongated morphology and some cells also showed vacuolation, $\times 100$. (d) Melanocytes after $21 \mathrm{~d}$ of culture showed accumulation of melanin and the rounded structures in the circles are dead cells due to melanin toxicity, $\times 100$ ).

The primary cells showed dendrite formation, cells connecting each other (Figure 1a). The first passage cells were maintained in 5\% serum. At this stage the cells showed maturation, high dendriticity and slight accumulation of melanin in the circles (Figure 1b). Generally the dividing cells showed polygonal to elongated morphology with vacuolation (Figure 1c). At 21 days of incubation, melanocytes showed the accumulation of melanin. Prominent rounded structures in circles (Figure 1d) were observed which might be dead cells. The cell death was likely due to the melanin toxicity or bursting of cells in the culture medium.

Moreover, significant increase in total melanin was also observed with L-cystiene in Hanwoo brown. On the other hand a significant increase was found in eumelanin when melanocytes were supplemented with L-cystiene in Hanwoo brown. Conversely, L-cystiene showed a significant suppression of eumelanin content in Hanwoo black but no significant change was found in Hanwoo brindle. However, a significant increase in eumelanin was found in Hanwoo brown by $\alpha-\mathrm{MSH}$ and nitric oxide treatments (Table 1 ).

The statistical significance of total melanin and

Table 1. Total and eumelanin contents $\left(\mu \mathrm{g} / 4 \times 10^{5}\right.$ cells) and their ratio in melanocytes from Black, Brindle and Brown Hanwoo muzzles treated with L-cysteine, $\alpha$-MSH and nitric oxide

\begin{tabular}{|c|c|c|c|c|c|c|}
\hline & & \multicolumn{3}{|c|}{ Coat color } & \multirow{2}{*}{ Av. SE } & \multirow{2}{*}{ F-value } \\
\hline & & Black & Brindle & Brown & & \\
\hline \multirow[t]{3}{*}{ Control } & Total melanin & $23.0^{\mathrm{aB}}$ & $21.6^{\mathrm{abB}}$ & $19.2^{\mathrm{bB}}$ & 0.806 & $5.84 *$ \\
\hline & Eumelanin & $20.0^{\mathrm{aA}}$ & $18.6^{\mathrm{aA}}$ & $5.5^{\mathrm{bB}}$ & 2.241 & $12.76^{* *}$ \\
\hline & Ratio & $0.309^{\mathrm{aAB}}$ & $0.298^{\mathrm{aB}}$ & $0.153^{\mathrm{bB}}$ & 0.007 & $167.96 * * *$ \\
\hline \multirow[t]{3}{*}{ L-cysteine } & Total melanin & $26.7^{\mathrm{aB}}$ & $24.0^{\mathrm{aB}}$ & $27.1^{\mathrm{aA}}$ & 1.745 & 0.94 \\
\hline & Eumelanin & $7.7^{\mathrm{bB}}$ & $21.7^{\mathrm{aA}}$ & $10.1^{\mathrm{bA}}$ & 3.605 & $4.29 *$ \\
\hline & Ratio & $0.314^{\mathrm{aAB}}$ & $0.275^{\mathrm{aC}}$ & $0.270^{\mathrm{aA}}$ & 0.014 & 2.82 \\
\hline \multirow[t]{3}{*}{$\alpha-\mathrm{MSH}$} & Total melanin & $38.7^{\mathrm{aA}}$ & $44.8^{\mathrm{aA}}$ & $23.0^{\mathrm{bB}}$ & 2.194 & $26.35 * *$ \\
\hline & Eumelanin & $12.2^{\mathrm{aAB}}$ & $13.9^{\mathrm{aA}}$ & $13.8^{\mathrm{aA}}$ & 2.379 & 0.17 \\
\hline & Ratio & $0.288^{\mathrm{abB}}$ & $0.317^{\mathrm{aAB}}$ & $0.282^{\mathrm{bA}}$ & 0.010 & 3.47 \\
\hline \multirow[t]{3}{*}{ Nitric oxide } & Total melanin & $39.2^{\mathrm{aA}}$ & $42.7^{\mathrm{aA}}$ & $22.1^{\mathrm{bB}}$ & 1.872 & $34.67 * * *$ \\
\hline & Eumelanin & $18.5^{\mathrm{aA}}$ & $14.9^{\mathrm{aA}}$ & $12.1^{\mathrm{aA}}$ & 2.345 & 1.89 \\
\hline & Ratio & $0.329^{\mathrm{aA}}$ & $0.323^{\mathrm{aA}}$ & $0.176^{\mathrm{bB}}$ & 0.008 & $116.99 * * *$ \\
\hline
\end{tabular}

${ }^{\mathrm{a}, \mathrm{b}}$ Means bearing a same letter within each row did not significantly differ ( $\left.\mathrm{p}>0.05\right)$.

${ }^{\mathrm{A}, \mathrm{B}}$ Means bearing a same letter for each measurement (i.e., total melanin, eumelanin and ratio) within each column did not significantly differ ( $\mathrm{p}>0.05$ ).

$* \mathrm{p}<0.05, * * \mathrm{p}<0.01, * * * \mathrm{p}<0.001$. 
Table 2. mRNA expression of $M C 1 R$, Try1, Try 2 and Try genes in arbitrary unit for melanocytes from Black, Brindle and Brown Hanwoo muzzles treated with L-cysteine, $\alpha$-MSH and Nitric oxide

\begin{tabular}{|c|c|c|c|c|c|c|}
\hline & & & Coat color & & $\mathrm{S}$ & $\Gamma$ \\
\hline & & Black & Brindle & Brown & AV. SE & F-value \\
\hline Control & $M C 1 R$ & $4,736^{\mathrm{aA}}$ & $5,242^{\mathrm{aA}}$ & $5,282^{\mathrm{aA}}$ & 752.1 & 0.16 \\
\hline & Tryl & $6,116^{\mathrm{aA}}$ & $6,081^{\mathrm{aA}}$ & $6,328^{\mathrm{aA}}$ & 356.2 & 0.14 \\
\hline & Try & $4,380^{\mathrm{aB}}$ & $4,413^{\mathrm{aB}}$ & $4,323^{\mathrm{aA}}$ & 1037.9 & 0 \\
\hline & Tyr 2 & $4,589^{\mathrm{aA}}$ & $5,462^{\mathrm{aA}}$ & $4,405^{\mathrm{aA}}$ & 965.9 & 0.34 \\
\hline L-cysteine & $M C 1 R$ & $2,899^{\mathrm{aB}}$ & $2,988^{\mathrm{aB}}$ & $3,186^{\mathrm{aB}}$ & 268.1 & 0.3 \\
\hline & Tryl & $6,634^{\mathrm{aA}}$ & $6,260^{\mathrm{aA}}$ & $6,388^{\mathrm{aA}}$ & 423.8 & 0.2 \\
\hline & Try & $1,635^{\mathrm{aC}}$ & $1,426^{\mathrm{aC}}$ & $1,706^{\mathrm{aB}}$ & 93.2 & 2.45 \\
\hline & Tyr2 & $1,745^{\mathrm{aB}}$ & $2,364^{\mathrm{aB}}$ & $2,407^{\mathrm{aB}}$ & 493.5 & 0.56 \\
\hline$\alpha-\mathrm{MSH}$ & $M C 1 R$ & $5,821^{\mathrm{aA}}$ & $5,630^{\mathrm{aA}}$ & $5,812^{\mathrm{aA}}$ & 350.6 & 0.09 \\
\hline & Tryl & $5,953^{\mathrm{aA}}$ & $5,842^{\mathrm{aA}}$ & $5,457^{\mathrm{aA}}$ & 320.4 & 0.66 \\
\hline & Try & $5,261^{\mathrm{aAB}}$ & $4,920^{\mathrm{aAB}}$ & $4,934^{\mathrm{aA}}$ & 641.7 & 0.09 \\
\hline & Tyr 2 & $6,110^{\mathrm{a}}$ & $6,099^{\mathrm{aA}}$ & $5,772^{\mathrm{aA}}$ & 163.2 & 1.38 \\
\hline Nitric oxide & $M C 1 R$ & $5,988^{\mathrm{aA}}$ & $6,398^{\mathrm{aA}}$ & $5,148^{\mathrm{aA}}$ & 518.2 & 1.51 \\
\hline & Tryl & $6,178^{\mathrm{aA}}$ & $6,194^{\mathrm{aA}}$ & $5,712^{\mathrm{aA}}$ & 233.7 & 1.37 \\
\hline & Try & $6,423^{\mathrm{abA}}$ & $6,730^{\mathrm{aA}}$ & $5,723^{\mathrm{bA}}$ & 233.7 & $4.7^{*}$ \\
\hline & Tyr2 & $5,844^{\mathrm{aA}}$ & $5,936^{\mathrm{aA}}$ & $5,107^{\mathrm{aA}}$ & 603.7 & 0.57 \\
\hline
\end{tabular}

${ }^{\mathrm{a}, \mathrm{b}}$ Means bearing a same letter within each row did not significantly differ ( $\left.\mathrm{p}>0.05\right)$.

${ }^{\mathrm{AB}}$ Means bearing a same letter for each gene (i.e., $M C 1 R$, Try1, Try, Try2) within each column did not significantly differ ( $\left.\mathrm{p}>0.05\right)$. $* \mathrm{p}<0.05$.

eumelanin in muzzle samples was determined (SAS Institute Inc., USA, 1997) and the effect of breed (i.e., coat color) on melanin content is presented in the current study (Table 1). Significant $(\mathrm{p}<0.05)$ variation in total melanin and eumelanin content among different phenotypes was observed. A significant increase was found in total melanin content when melanocytes were treated with nitric oxide and $\alpha-\mathrm{MSH}$ in Hanwoo black and brindle.

Furthermore, we studied the mRNA expression of MC1R, Tyrp1, Tyrp2 and Try genes in melanocytes treated with L-cysteine, $\alpha$-MSH and nitric oxide from at least three unrelated Hanwoo phenotypes. Table 2 lists the mRNA expression of MC1R, Tyr, Tyrpl and Tyrp 2 genes in melanocytes culture for black, brindle and brown Hanwoo treated with L-cysteine, $\alpha$-MSH and nitric oxide, respectively. Semi-quantitative RT-PCR showed the up regulation of Tyr in all selected cattle by nitric oxide and in $\alpha$-MSH treatments, whereas Tyr, Tyrp-2 and MC1R genes are down regulated in L-cysteine treated melanocytes from all the three phenotypes (Table 2).

To get more insight into the changes of melanocytes culture, confocal microscopic studies were done. The numbers of dead cell assessed by confocal microscopy after propidium iodide staining (Figure 2) were tabulated (Table
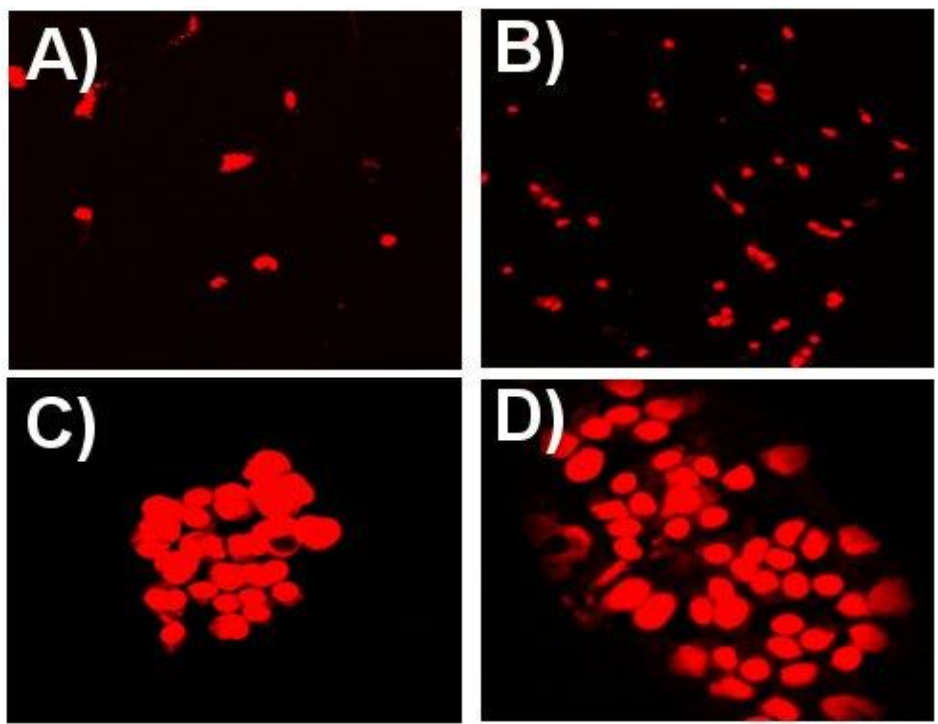

Figure 2. Representative figures of melanocytes treated with $\alpha$-MSH. Cells were observed by a confocal microscope after PI staining. Micrographs' showing dead cells at different incubation time (a) 24 h, $\times 200$; (b) 48 h, $\times 200$; (c) 72 h, $\times 400$; (d) 96 h, $\times 400$, respectively. 
3) up to $96 \mathrm{~h}$ of incubation period. Significant increases $(p<0.05)$ were found in the number of dead cells with an increase in incubation time in both the groups. A significant increase was observed in dead cells from 24 to $72 \mathrm{~h}$ when cells were treated with nitric oxide and $\alpha$-MSH respectively, however, with L-cysteine the values were non significant. In the present study, the highest number of dead cells was obtained when the melanocyte culture was supplemented with $\alpha$-MSH (Figure 2) and also after $96 \mathrm{~h}$ in all treated cultures.

\section{DISCUSSION}

Earlier reports on melanocytes and melanoma cells in culture mainly described their typical structure and metabolic features (Bucek and Vrba, 1976; Bhavanandan, 1981; Waldrep and Kaplan, 1986; Hu et al., 1987). Korean Hanwoo cattle exhibit three different coat colors and concomitant muzzle colors (Seo et al., 2007; Mohanty et al., 2008) but the behavior of melogenic factors on Hanwoo muzzle melanocytes were never before investigated in culture. We therefore, investigated the effect of $\alpha$-MSH, nitric oxide and L-cysteine on them.

Most of the protocols used for the various melanocyte cultures (Bucek and Vrba, 1976; Bhavanandan, 1981; Waldrep and Kaplan, 1986; Hu et al., 1987; Mohanty et al., 2008) involved the use of mitogens such as cholera toxin. In this study, melanocytes were grown without addition of cholera toxin. Cholera toxin mimics melanocyte stimulating hormone in inducing differentiation in melanoma cells and alter morphology of melanoma cells in culture. To avoid toxin related problems, melanocytes were grown without the supplementation of cholera toxin but the growth rate was very slow. To obtain primary cultures enriched with melanocytes, most of the dermis was removed from the muzzle specimens; this minimizes fibroblast contamination. An overnight trypsinization was carried out at room temperature to enhance the melanocyte ratio. For better assessment of differentiation, only fully differentiated melanocytes were used in the present study. Selective differentiation of melanocytes was obtained by using trypsin $(0.25 \%)$. Hanwoo muzzle tissues were cultured with trypsin $(0.25 \%)$ solution at $4^{\circ} \mathrm{C}$ for $24 \mathrm{~h}$. Confluent primary cultures were submitted to trypsin treatment and passaged. If residual keratinocytes were still observed after this passage, a further trypsinization was carried out. In the present study trypsin $(0.25 \%)$ produced the best results. Moreover, the advantage of the trypsin digestion method is that it is a relatively simple method and easy to perform. Also geneticin effectively eliminated contaminant cells, mainly fibroblasts cells, without toxic effects on melanocyte culture. So the method used in this study provided pure culture with good growth and melanogenic capacities in vitro.

In mammals, melanogenesis is highly regulated and complex phenomenon occurring within specialized cells termed melanocytes. The melanin synthesis in the melanocytes is under genetic control. This control is also maintained when the cells are removed from their natural environment and grown in culture. Many studies of melanogenesis by epidermal melanocytes have been reported and it is well established that epidermal melanocytes do produce melanin in vivo and in vitro. Hu et al. (1995) reported that the culture system is capable of generating large numbers of human uveal melanocytes cells in pure culture. For an accurate investigation of melanogenes in vitro, it is essential to generate a large population of melanocytes in pure culture. Study of melanogenesis by uveal melanocytes in vitro has been hampered by their low proliferative potential and the tendency for contamination with other cell types under usual culture conditions. Melanin content and the production of melanin by uveal melanocytes in vitro apparently are influenced by racial and genetic factors because uveal melanocytes from a black donor showed significantly higher melanin content, rate of melanin production, and tyrosinase activity, as well as larger melanosomal size, than seen in uveal melanocytes derived from white donors. The content of melanin per cell in cultured uveal melanocytes is not only determined by the production of melanin but also by growth rate. In stationary cells, the melanin produced accumulates within the cell and results in a rapid increase of melanin content per cell. In growing cells, the melanin is diluted to daughter cells during division. If the melanin production rate equals the rate of dilution, the melanin content per cell would remain

Table 3. Number of dead cells assessed by confocal microscopy after propidium iodide staining

\begin{tabular}{|c|c|c|c|c|c|c|}
\hline & \multicolumn{4}{|c|}{ Incubation time $(\mathrm{h})$} & \multirow{2}{*}{ Av. SE } & \multirow{2}{*}{ F-value } \\
\hline & 24 & 48 & 72 & 96 & & \\
\hline Control & $43.3^{\mathrm{bA}}$ & $32.1^{\mathrm{cD}}$ & $30.0^{\mathrm{cD}}$ & $51.6^{\mathrm{aD}}$ & 1.902 & $28.07 * * *$ \\
\hline L-cysteine & $28.9^{\mathrm{cB}}$ & $37.1^{\mathrm{bC}}$ & $36.8^{\mathrm{bC}}$ & $72.0^{\mathrm{aC}}$ & 0.638 & $909.48 * * *$ \\
\hline$\alpha-\mathrm{MSH}$ & $40.8^{\mathrm{dA}}$ & $60.0^{\mathrm{cA}}$ & $71.1^{\mathrm{bA}}$ & $119.4^{\mathrm{aA}}$ & 1.633 & $420.98 * * *$ \\
\hline Nitric oxide & $38.1^{\mathrm{cA}}$ & $43.8^{\mathrm{bB}}$ & $44.2^{\mathrm{bB}}$ & $88.2^{\mathrm{aB}}$ & 1.720 & $182.97 * * *$ \\
\hline
\end{tabular}

\footnotetext{
${ }^{\mathrm{a}, \mathrm{b}}$ Means bearing a same letter within each row did not significantly differ $(\mathrm{p}>0.05)$.

${ }^{\mathrm{A}, \mathrm{B}}$ Means bearing a same letter within each column did not significantly differ $(\mathrm{p}>0.05)$. *** $\mathrm{p}<0.001$.
} 
unchanged. In rapidly growing cells, if the dilution rate is greater than that of melanin production, melanin content per cell would decrease. Thus from the earlier findings $(\mathrm{Hu}$ et al., 1995) we are able to conclude that several factors control the complex melanogenesis process in biological systems and if we are capable of controlling these factors in culture, melanogenesis could be controlled in culture too. However, the chances are mutations are always higher in culture than the natural biological system.

To gain more insight into the changes of melanin composition during culture we investigated the influence of L-cystine, $\alpha$-MSH and nitric oxide on Hanwoo muzzle melanocytes. It was observed that the total melanin and eumelanin production varies with treatments in different breeds (Table 1). Stimulation of melanogenesis by $\alpha-\mathrm{MSH}$ was reported to favor a switch to the production of greater levels of eumelanogenic melanin and an increase in tyrosinase activity has been considered to be one of its mechanisms (Hunt et al., 1995; Thody and Graham, 1998). Besides $\alpha$-SH, Nitric oxide (Romero-Graillet et al., 1998; Sasaki et al., 2000) is also a reported melanogenic factor and its also reported that nitric oxide contributes to eumelanogenesis enhancement. Our results are in complete agreement with studies of Romero-Graillet et al. (1998) and Sasaki et al. (2000) especially in case of Hanwoo brown melanocytes.

On the other hand an increase in total melanin content in Hanwoo brown and a significant $(\mathrm{p}<0.05)$ decrease of eumelanin content in Hanwoo black with L-cystine was observed (Table 1) in the current study. A decline in eumelanin with L-cystine has also been explained earlier (Hunt et al., 1995) and was demonstrated that L-cystine plays important role in pheomelanin production during melanogenesis. Moreover, mammalian pigmentation is controlled by the concerted action of TYR, TYRPI and TYRP-2 in producing eumelanin and pheomelanin in melanocytes. We analyzed and found that $T y r$ is down regulated by L-cystine and up regulated by the nitric oxide and $\alpha-\mathrm{MSH}$ in all the three breeds of Hawnoo. Tyrosinase is the rate-limiting enzyme in the melanogenesis pathway and high levels of this enzyme are required for the production of eumelanin, whereas low enzyme levels result in the production of pheomelanin (Hearing and Tsukamoto, 1991; Jackson, 1993). Tyrosinase activity is regulated by the melanocortin 1 receptor (MC1R or $\alpha$-MSHR), whose stimulation by $\alpha$-melanocyte-stimulating hormone leads to the production of eumelanin (Burchill et al., 1986).

Pheomelanin is produced either in absence of $\alpha-\mathrm{MSH}$ stimulation or as result of a non-functional MC1R receptor (Robbins et al., 1993). Furthermore, eumelanogenesis is thought to be stimulated by the induction of tyrosinaserelated enzymes (TRP-1 and TRP-2). It has also been reported that $\alpha$-MSH has little effect on the expression of
TRP-1 or TRP-2. Conversely, L-cystine concentration also has a strong influence on tyrosinase activity (Sieji et al., 1969). Seiji et al. (1969) demonstrated the direct inhibition of tyrosinase by cystine under in vitro condition. Whereas, the inactivation of the enzyme by the interaction of sulfhydryl compounds has been demonstrated by different authors (Jerjil et al., 1984; Jara et al., 1988; del et al., 1993). The regulation role of sulfhydryl compounds has already been described by Flesch et al (Flesch and Rothman, 1948). Del Marmol et al. (Del et al., 1993) have also shown that by the depletion of cystine in (hams F-10) medium of melanoma cell lines, tyrosinase activity was increased.

Interestingly, our findings are consistent with previous results on the levels of tyrosinase expression in all selected breeds. However, at present there is no adequate explanation as to why black and brindle cattle melanocytes failed to show any response to nitric oxide and $\alpha$-MSH. It appeared to us that basal levels of tyrosinase and melanin content are unrelated to each other. Moreover, in the present study no convincing reason was found for the suppression of eumelanin production in black cattle by $\alpha$-MSH. Additionally, death of melanocytes has been demonstrated earlier in culture (Nordlund et al., 2006) which might be due to accumulation of melanin that becomes toxic to the cells. Therefore, a probable reason for the death of melanocytes observed in the present study may be partly due to the bursting of cells in culture and partly by melanin toxicity. Actually it is already reported in the literature (Wick et al., 1977) that L-dopa, an intermediate in the biosynthesis of the pigment melanin, has highly selective inhibition of growth for pigmented cell lines as compared to the no-pigmented cells. There is a correlation between toxicity and the extent of incorporation of radioactively labeled L-dopa by each line. However, it is difficult to conclude from the present study that the real cause of cell toxicity is melanin accumulation. Further detailed investigations would be required.

In summary, the present investigation demonstrates that the nature of pigmentation is dependent on the stimulus. Eumelanogenesis increases significantly with $\alpha-\mathrm{MSH}$ and nitric oxide which is accompanied by increase in tyrosinase activity. Finally, it can be concluded that melanogenesis can be stimulated in culture by the melanogenic factors viz., $\alpha-\mathrm{MSH}$, nitric oxide and L-cystine in muzzle melanocytes of Hanwoo cattle.

\section{ACKNOWLEDGEMENT}

It should be acknowledged that this work was partly supported by a grant from the Korea Institute of Planning and Evaluation for Technology in Food, Agriculture, Forestry and Fisheries (No. 306011-05-5-SB010) and FTA issue project (No. PJ907055), Rural Development 
Administration, Republic of Korea.

\section{REFERENCES}

Barsh, G. S. 2006. Regulation of pigment type switching by agouti, melanocortin signaling, attractin and mahoganoid. In: The Pigmentary System, 2nd edn (Ed. J. J. Nordlund, R. E. Boissy, V. J. Hearing, R. A. King, W. S. Oetting and J. P. Ortonne) (Massachusetts: Blackwell Publishing), 395-409.

Becerril, C. M., C. J. Wilcox, T. J. Lawlor, G. R. Wiggans and D. W. Webb. 1993. Effects of percentage of white coat color on Holstein production and reproduction in a subtropical environment. J. Dairy Sci. 76:2286-2291.

Bhavanandan, V. P. 1981. Glycosaminoglycans of cultured human fetal uveal melanocytes and comparison with those produced by cultured human melanoma cells. Biochemistry 20:55955602.

Burchill, S. A., A. J. Thody and S. Ito. 1986. Melanocytestimulating hormone, tyrosinase activity and the regulation of eumelanogenesis and phaeomelanogenesis in the hair follicular melanocytes of the mouse. J. Endocrinol. 109:15-21.

Bucek, J. and M. Vrba. 1976. Ultrastructure of human uveal melanomas cultivated in vitro. Neoplasma 23:109-118.

Chhajlani, V. and J. E. S. Wikberg. 1992. Molecular cloning and expression of the human melanocyte stimulating hormone receptor cDNA. FEBS Lett. 309:417-420.

Chomczynski, P. and N. Sacchi. 1987. Single step method of RNA isolation by acid guanidinium thiocyanate-phenol-chloroform extraction. Anal. Biochem. 161:156-159.

Del, Marmol, V., F. Solano, A. Sels, G. Huez, A. Libert, F. Lejeune and G. Ghanem. 1993. Glutathione depletion increases tyrosinase activity in humane melanoma cells. J. Invest. Dermatol. 101:871-874.

D’Orazio, J. A., T. Nobuhisa, R. Cui, M. Arya, M. Spry, K. Wakamatsu, V. Igras, T. Kunisada, S. R. Granter and E. K. Nishimura. 2006. Topical drug rescue strategy and skin protection based on the role of Mc1r in UV-induced tanning. Nature 443:340-344.

Endler, J. A. 1991. Variation in the appearance of guppy color patterns to guppies and their predators under different visual conditions. Vision Res. 31:587-608.

Flesch, P. and S. Rothman. 1948. Role of sulfhydryl compounds in pigmentation. Science 108:505-506.

Hearing, V. J. and K. Tsukamoto. 1991. Enzymatic control of pigmentation in mammals. FASEB J. 5:2902-2909.

Hoekstra, H. E. 2006. Genetics, development and evolution of adaptive pigmentation in vertebrates. Heredity 97:222-234.

Hu, F., D. J. Teramura and K. Mah. 1987. Normal uveal melanocytes in culture. Pigment Cell Res. 1:94-103.

Hu, D. N., S. A. Mc. Cormick, S. J. Orlow, S. Rosemblat, A. Y. Lin and K. Wo. 1995. Melanogenesis by human uveal melanocytes in vitro. Invest. Ophthalmol. Vis. Sci. 36:931-938.

Hunt, G., S. Kyne, S. Ito, K. Wakamatsu and C. Thody. 1995. Eumelanin and pheomelanin contents of humane epidermis and cultured melanocytes. Pigment Cell Res. 8:202-208.

Hunt, G., S. Kyne and K. Wakamatsu. 1995. Nle ${ }^{4} \mathrm{Phe}^{7}$ $\alpha$-Melanocyte-stimulating hormone increases the eumelanin: pheomelanin ratio in cultured human melanocytes. J. Invest. Dermatol. 104:83-85.
Ian, Freshney R. 1994. Culture of animal cells: a manual of basic technique. Third Edition. A John Wiley \& Sons, Inc., Publication, USA.

Ito, S. and K. Fujita. 1985. Microanalysis of eumelanin and pheomelanin in hair and melanomas by chemical degradation and liquid chromatography. Anal. Biochem. 144:527-536.

Ito, S., K. Wakamatsu and H. Ozeki. 2000. Chemical analysis of melanins and its application to the study of the regulation of melanogenesis. Pigment Cell Res. 13:103-109.

Ito, S. 2003. The IFPCS presidental lecture: a chemist's view of melanogenesis. Pigment Cell Res. 16:230-236.

Jackson, I. J. 1993. Colour-coded switches. Nature 362:587-588

Jackson, I. J. 1994. Molecular and developmental genetics of mouse coat color. Annu. Rev. Genet. 28:189-217.

Jackson, I. J. 1997. Homologous pigmentation mutations in human, mouse and other model organisms. Hum. Mol. Genet. 6:16131624.

Jara, J. R., P. Aroca, F. Solano, J. H. Martinez and J. A. Lozano. 1988. The role of sulfhydryl compounds and the intermediates of the pathway. Biochim. Biophys. Acta 967:296-303.

Jerjil, B., C. Lindbladh, H. Rorsman and E. Rosengren. 1984. Inactivation of humane tyrosinase by cysteine, protection by dopa and tyrosine. Acta. Derm. Veuereol. 64:155-182.

Klungland, H. and D. I. Vage. 2000. Molecular genetics of pigmentation in domestic animals. Curr. Genomics 1:223.

Lin, J. Y. and D. E. Fisher. 2007. Melanocyte biology and skin pigmentation. Nature 445:843-850.

Mohanty, T. R., K. S. Seo, K. M. Park, T. J. Choi, H. S. Choe, D. H. Baik and I. H. Hwang. 2008. Molecular variation in pigmentation genes contributing to coat colour in native Korean Hanwoo cattle. International Society for Animal Genetics. Anim. Genet. 39:550-553.

Mountjoy, K. G., L. S. Robbins, M. T. Mortrud and R. D. Cone. 1992. The cloning of a family of genes that encode the melanocortin receptors. Science 257:1248-1251.

Mundy, N. I. 2005. A window on the genetics of evolution: MC1R and plumage colouration in birds. Proc. Biol. Sci. 272:16331640.

Nordlund, J. J., R. E. Boissy and V. J. Hearing et al. 2006. The pigmentary system. 2nd edn. Black well Publishers.

Protas, M. E. and N. H. Patel. 2008. Evolution of coloration patterns. Annu. Rev. Cell Dev. Biol. 24:425-446.

Robbins, L. S., J. H. Nadeau, K. R. Johnson, M. A. Kelly, L. Roselli-Rehfuss, E. Baack and K. G Mountjoy, et al. 1993. Pigmentation phenotypes of variant extension locus alleles result from point mutations that alter $\mathrm{MSH}$ receptor function. Cell 72:827-834.

Romero-Graillet, C., E. Aberdam, N. Biagoli, W. Massabni, J. P. Ortonne and R. Ballotti. 1996. Ultraviolet B radiation acts through the nitric oxide and cGMP signal transduction pathway to stimulate melanogenesis in human melanocytes. J. Biol. Chem. 271:28052-28056.

Roulin, A. 2004. The evolution, maintenance and adaptive function of genetic colour polymorphism in birds. Biological Reviews 79:815-848.

Safran, R. J. and K. J. McGraw. 2004. Plumage coloration, not length or symmetry of tail-streamers, is a sexually selected trait in North American barn swallows. Behav. Ecol. 15:455461.

SAS Applied Statistics and the SAS Programming Language. 1997. 
SAS Institute Inc., Cary, NC, USA.

Sasaki, M., T. Horikoshi, H. Uchiwa and Y. Miyachi. 2000. Upregulation of tyrosinase gene by nitric oxide in human melanocytes. Pigment Cell Res. 13:248-252.

Seo, K. S., T. R. Mohanty, T. Choi and I. H. Hwang. 2007. Biology of epidermal and hair pigmentation in cattle: a mini-review. Vet. Dermatol. 18:392-400.

Sieji, M., T. Yoshida, H. Itakura and I. Tishikatsu. 1969. Inhibition of melanin formation by sulphydryl compounds. J. Invest. Dermatol. 52:280-286.

Silvers, W. K. 1979. The coat colors of mice: a model for mammalian gene action and interaction, Springer-Verlag.
Thody, A. J. and A. Graham. 1998. Does alpha-MSH have a role in regulating skin pigmentation in humans? Pigment Cell Res. 11:265-274.

Waldrep, J. C. and H. J. Kaplan. 1986. Human choroidal melanocytes in tissue culture. Curr. Eye Res. 5:587-594.

Wick, M. M., L. Byers and E. Frei. 1997. L-dopa: selective toxicity for melanoma cells in vitro. Science 197(4302):468469.

Wickelgren, I. 2007a. Skin biology. A healthy tan? Science 315:1214-1216.

Wickelgren, I. 2007b. Skin biology. Why I have red hair, need to avoid the sun, and shouldn't commit a crime. Science $315: 1215$. 